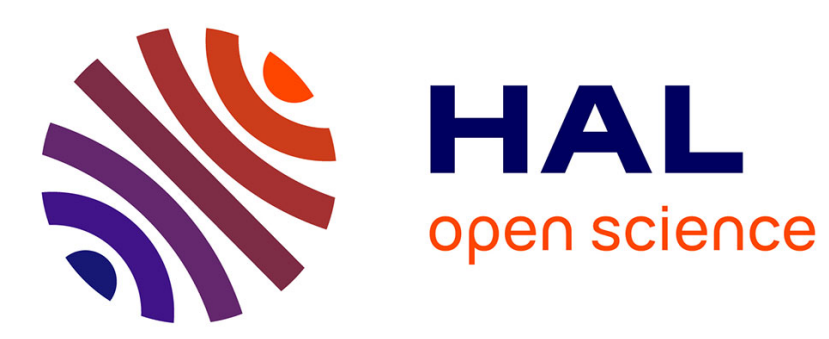

\title{
Temperature dependence of elastic strain and damage build-up in He implanted AlN
}

S. Jublot-Leclerc, G. Bouhali, F. Pallier, A. Declémy

\section{To cite this version:}

S. Jublot-Leclerc, G. Bouhali, F. Pallier, A. Declémy. Temperature dependence of elastic strain and damage build-up in He implanted AlN. J.Eur.Ceramic Soc., 2021, 41 (1), pp.259-267. 10.1016/j.jeurceramsoc.2020.08.010 . hal-03011061

\section{HAL Id: hal-03011061 \\ https://hal.science/hal-03011061}

Submitted on 24 Nov 2020

HAL is a multi-disciplinary open access archive for the deposit and dissemination of scientific research documents, whether they are published or not. The documents may come from teaching and research institutions in France or abroad, or from public or private research centers.
L'archive ouverte pluridisciplinaire HAL, est destinée au dépôt et à la diffusion de documents scientifiques de niveau recherche, publiés ou non, émanant des établissements d'enseignement et de recherche français ou étrangers, des laboratoires publics ou privés. 


\title{
Temperature dependence of elastic strain and damage build-up in He implanted AIN
}

\author{
S. Jublot-Leclerc ${ }^{1, a}$, G. Bouhali ${ }^{1}$, F. Pallier ${ }^{1}$, A. Declémy ${ }^{2}$ \\ ${ }^{1}$ Université Paris-Saclay, CNRS/IN2P3, IJCLab, 91405 Orsay, France \\ 2 Institut Pprime, département Physique et Mécanique des Matériaux, CNRS-Université de Poitiers-ENSMA, BP \\ 30179, 86962 Futuroscope Chasseneuil Cedex 05, France
}

Keywords : He implantation, AlN, X-Ray Diffraction, Transmission Electron Microscopy, temperature

\begin{abstract}
The elastic strain build-up and damage induced by $50 \mathrm{keV} \mathrm{He}$ implantation at RT and $550^{\circ} \mathrm{C}$ into (0001)AlN were studied using a combination of XRD experiments, XRD simulation, and TEM experiments. Evidence for strong dynamic annealing with efficient point defect recombination is reported at RT. The point defect recombination is found to be enhanced with increasing implantation temperature where He concentration is low, indicating increased mobility of interstitial-type defects and resulting in low strain. A reversed effect is observed for He concentration exceeding 5 at.\% (3 at.\%) at RT $\left(550^{\circ} \mathrm{C}\right)$ : thermally activated mechanisms related to the nucleation and growth of $\mathrm{He}-\mathrm{V}$ complexes overcome the point defect recombination and promote the strain and damage build-up. At $1 \times 10^{17} \mathrm{~cm}^{-2}$, only clusters of interstitials are observed at RT, whilst bubbles and basal stacking faults are additionally formed at $550^{\circ} \mathrm{C}$ for a critical He concentration estimated to be close to $4-6$ at.\%.
\end{abstract}

\footnotetext{
${ }^{a}$ Author to whom correspondence should be addressed. Electronic address: stephanie.jublotleclerc@ijclab.in2p3.fr
} 


\section{Introduction}

Group III-nitrides and their alloys have gained great interest as direct band gap semiconductors with outstanding properties making them ideally suited for electronic and optoelectronic devices, in particular light emitting diodes [1-3]. They are increasingly used in power electronics and high electron mobility transistors (HEMTs) [4] and are potential candidates for high-temperature, high-power, highfrequency, and short-wavelength electronics under radiation environments in space [5-6]. Their known resistance to radiation-induced amorphisation [7] also makes them suitable as insulating and optical materials to be used in future fusion reactors in a variety of applications among which diagnostic systems. Other applications in radiative environments include insulating coatings in fusion reactors. AlN, in particular, has been proposed as an insulating coating in fusion reactor concepts with selfcooled liquid metals to prevent the permeation of tritium as well as minimize the magnetohydrodynamic force that occurs when a conductive fluid is circulated in a magnetic field and that would hinder the cooling by the liquid metal [8]. These applications in fusion reactors require that the material resists the effects of $14 \mathrm{MeV}$ neutrons with the production of both $\mathrm{He}$ and $\mathrm{H}$ at high rates [9-10]. The materials facing plasma will also be exposed to intense fluxes of low energy $\mathrm{He}$ and $\mathrm{H}$. It is consequently imperative to clarify the mechanisms responsible for the degradation of the material properties under irradiation and gas injection. From the point of view of the microstructural evolution, some neutron irradiation studies were performed on AlN [11-13], as well as mostly optically active rare earth, dopant and heavy ion implantations [7, 14-20], nearly all of which have highlighted the particular complexity of the induced damaging mechanisms mostly related to efficient dynamic annealing processes. However, whilst potentially detrimental to the mechanical integrity of the material, the effects of gas injection in AlN are largely unaddressed with only scarce studies on He implanted sintered or polycrystalline AlN [21-24], and only a few are reported for other He or H-implanted nitrides [25-28]. The radiation effects at elevated temperatures, which are of particular concern for nuclear applications, were also barely investigated and the few reports mostly deal with thermal annealing of damage induced by irradiation [16, 29-30]. It is known that structural alloys will be submitted to temperatures of a few hundred degrees in experimental fusion devices such as ITER (up to $350-550^{\circ} \mathrm{C}$ in the Test Blanket Module) and DEMO reactors (up to $550-700^{\circ} \mathrm{C}$ ). The temperature to which AlN would be submitted in fusion reactors depends on the design of the reactor and on its use as a coating or in diagnostic systems, but it should be able to sustain similar temperatures at least. The present publication reports a microstructural study of He implantation into AlN monocrystalline layers, comparing the results obtained after implantations at $\mathrm{RT}$ and $550^{\circ} \mathrm{C}$ and taking advantage of a combination of Transmission Electron Microscopy (TEM) and X-Ray Diffraction (XRD) experiments. XRD has already been shown to be particularly useful in microstructural investigation of ion implanted materials as a method that is sensitive to elastic strain at very low damage level, before the formation of defects and damage detectable by TEM or RBS/C [15, 31-35]. He implantation at RT and $550^{\circ} \mathrm{C}$ in the chosen fluence range into AlN induces non-negligible elastic strains that can be followed to give some valuable information on the material behavior under implantation. In this study, the coupling of XRD experiments and simulation, in particular, bring insights into the effects of He injection on the mechanisms of damage and strain build-up in AlN. 


\section{Experimental procedures}

Two different types of monocrystalline (0001) AlN templates, both undoped and grown on sapphire substrates, were used in this study : (i) an epitaxial $1 \mu \mathrm{m}$-film grown by Plasma Vapor Deposition of Nanocolumns (PVDNC) provided by MTI corporation, and, (ii) an epitaxial 4-5 $\mu \mathrm{m}$-thick layer provided by MSE supplies LLC. The FWHM of rocking curves are given by MSE supplies as < 350 arcsec and $<450$ arcsec for the (0002) and (1012) reflections, respectively, with a screw dislocation density of about $5.5 \times 10^{7} \mathrm{~cm}^{-2}$, and edge dislocation density of $\sim 1.8 \times 10^{9} \mathrm{~cm}^{-2}$. MTI corporation gives rocking curves FWHM of 300 arcsec and 1400 arcsec for (0002) and (1012) reflections, respectively. Both MTI and MSE specimens show a high density of native threading dislocations throughout the AIN layer by TEM (see Fig.1(a) and (c) for MTI). The density is exceptionally high in the MTI template (Fig.1(c)), considerably lower in comparison in the MSE template (Fig.2(b)).

Specimens from both MTI corp. and MSE supplies were implanted in the same implantation runs with $50 \mathrm{keV} \mathrm{He}$ ions on the IRMA accelerator of the JANNuS-Orsay/SCALP platform [36-37] at IJCLab (formerly CSNSM). Implantations were performed at room temperature (RT) as well as $550^{\circ} \mathrm{C}$ to fluences ranging from $2 \times 10^{16}$ to $1 \times 10^{17} \mathrm{~cm}^{-2}$. Implantations were performed at $7^{\circ}$ off the $(0001)$ surface normal to avoid any channeling effect, with an ion flux of $1 \times 10^{13}$ ions. $\mathrm{cm}^{-2} . \mathrm{s}^{-1}$ to minimize the heating during the RT implantation runs.

The depth distribution of vacancy and He concentrations calculated by SRIM [38] in full cascades mode were displayed in a previous publication (see Fig. 1 in [39]). The mean projected range of ions, $R_{P}$, and the peak of damage, $R_{D}$, are estimated to be close to 280 and $260 \mathrm{~nm}$, respectively. The maximum $\mathrm{He}$ concentration is close to 8 at. $\%$ at the fluence of $1 \times 10^{17} \mathrm{~cm}^{-2}$. The number of displacements per atom at the peak damage reaches $\sim 2$ at this fluence, using displacement energies of 94 and $38.8 \mathrm{eV}$ for aluminum and nitrogen atoms, respectively [40].

TEM specimens were prepared in cross-section by standard tripod mechanical polishing. The temperature was maintained as low as possible, i. e., lower than $80^{\circ} \mathrm{C}$, during all the steps requiring gluing and unglueing. The cross-section specimens were finally thinned down to electron transparency using Gatan PIPS Ar ion milling at $4 \mathrm{keV}$. TEM experiments were carried out on a Tecnai $\mathrm{G}^{2} 20$ Twin microscope at the JANNuS-Orsay/SCALP facility.

XRD experiments were carried out at Pprime in the Bragg (reflection) geometry on an automated laboratory-made two-circle goniometer with the radiation $\mathrm{K}_{\mathrm{a} 1}$ of copper $(1=1.5405 \AA)$ provided by a $5 \mathrm{~kW}$ RIGAKU RU-200 generator with a vertical linear focus in combination with a quartz monochromator. Previous X-ray reciprocal space mapping experiments on ion implanted AIN films have shown that the implantation-induced lattice strain is only directed along the surface normal direction (reciprocal space map not shown in [39], [41]). $\theta-2 \theta$ scans were carried out near the (0002) Bragg reflection $\left(2 \theta_{\mathrm{B}}=36.02^{\circ}\right)$ using 0.005 stepping motors. The sapphire substrate does not diffract in the vicinity of this reflection and the penetration depth of X-rays for this reflection is significantly larger than the implanted layer. This enables relative measurements of the normal strain in the surface implanted layer in comparison with the underlying AIN material that is not strained by implantation. According to the Bragg's law, the strain along the surface normal, $\varepsilon_{\mathrm{N}}$, is directly determined by plotting the $\theta-2 \theta$ curves as a function of $\mathrm{q}_{[0001]} / \mathrm{H}_{(0002)}$, where $\mathrm{q}_{[0001]}$ is the deviation from the reciprocal lattice 
vector $\mathrm{H}_{(0002)}$ of the (0002) planes in the direction of the sample surface. In addition to strain, $\mathrm{XRD}$ curves carry information of disorder (clustering of defects, amorphisation, etc.) via the static DebyeWaller factor Wh that weights the scattered intensity [34, 42-43]. The XRD curves were manually fitted using a web-based program written by S. Stepanov [44]. The simulation enables to obtain the strain profiles as a function of depth from the varying interference fringe periods observed on XRD curves. The program implements a "discrete" algorithm : the damaged layer of the crystal is divided into sublayers of given parameters among which thickness, normal strain and Wh. This strain profile is progressively modified until the calculated XRD curve fits the experimental one. Although high accuracy is obtained on the width of the strain profiles, the exact position of the strain profiles with respect to the sample surface cannot be accurately determined from such X-ray data. As the normal strain partly results from the defects generated by implantation, the strain profiles were initially centered on the position of the peak damage calculated by SRIM, and, more generally, every simulation was started with a strain profile proportional to the damage or vacancy profile calculated by SRIM before being modified for better fitting.

\section{Results}

\subsection{TEM results}

Cross-section thin foils were produced for three He implantation conditions on either MTI or MSE specimens : (i) implantation at RT to the fluence of $1 \times 10^{17} \mathrm{~cm}^{-2}$, (ii) implantation at $550^{\circ} \mathrm{C}$ to the fluence of $2 \times 10^{16} \mathrm{~cm}^{-2}$, and, (iii) implantation at $550^{\circ} \mathrm{C}$ to the fluence of $1 \times 10^{17} \mathrm{~cm}^{-2}$. For the second of these conditions, $550^{\circ} \mathrm{C}-2 \times 10^{16} \mathrm{~cm}^{-2}$, nothing is visible on conventional TEM micrographs, not even a contrasted layer (not shown). The material appears undamaged. In contrast, the other two conditions of implantation, both at high fluence, have a visible damaging effect on the microstructure. At RT-1 $\times 10^{17}$ $\mathrm{cm}^{-2}$, a contrasted layer can be observed in two-beam condition using $\mathbf{g}=0002$, as reported in Fig.1(a) in weak beam dark field (WBDF). A magnification of the damaged layer shows unresolvable defects in the form of dots that could be either clusters of point defects or small dislocation loops (Fig.1(b)). They are mainly contained in a deep layer, as shown in Fig.1(a,b), but defects are also present in lower concentration up to the surface of the specimen. A weak beam dark field performed using $\mathbf{g}=1 \overline{1} 00$, as reported in Fig.1(c), also shows a contrasted damaged layer, which is rather faint in comparison to the layer of defects observed with $\mathbf{g}=0002$, and with no visible dot-like defects. At the same fluence of $1 \times 10^{17} \mathrm{~cm}^{-2}$ and at $550^{\circ} \mathrm{C}$, similar features are observed in two beam condition with $\mathbf{g}=0002$, i. e., defects in the form of dots that are mainly located in a deep layer, as shown in Fig.2(a). A two-beam condition using $\mathbf{g}=1 \overline{1} 00$ also shows a deep contrasted damaged layer, as reported in Fig.2(b), in bright field and WBDF. Unlike the RT condition, this damaged layer has a strong contrast, and defects in the form of small segments can be distinguished. They are frequently observed in nitrides and were previously identified as being basal stacking faults (BSFs) [Refs in 39, 45]. In this orientation (Fig.2(b)), defects seem also present up to the surface of the specimen, but they are in far less concentration than in the main defect layer, and also much smaller. In addition to these extended defects, bubbles are also visible out of focus in a deep layer of the specimen, as shown in Fig.2(c). These bubbles are very small, lower than $1 \mathrm{~nm}$ in diameter, close to the limit of resolution that is induced by the surface roughness of the TEM thin foil. An average size of bubbles of 0.6-0.8 nm can however be estimated when measured 
on micrographs taken with a relatively low value of defocus. These bubbles are aligned along a rough, but not strict, direction parallel to the basal plane, with alignments up to a few tens of nm. Although it is difficult to conclude with these conditions in cross-section, rather than linear alignments, they are likely to be planar alignments of bubbles along (0002) planes. Such alignments of bubbles in basal planes were already previously reported in other He-implanted ceramics [9, 46-47]. These alignments of bubbles are mainly observed in a layer of material that is located between $240-250$ and $330 \mathrm{~nm}$ in depth. This exactly coincides with the main layers of defects observed in two-beam conditions using either $\mathbf{g}=0002$ or $\mathbf{g}=1 \overline{1} 00$. In addition, it also coincides with the main layers of defects observed at the same fluence at RT in Fig.1, which, for both $\mathbf{g}$ vectors, extend from 240-250 to $310 \mathrm{~nm}$ in depth. When compared to SRIM calculations, this corresponds to an intermediate location between the peak He concentration and the peak vacancy concentration. For all the studied conditions, no amorphisation was detected from the diffraction patterns.

\subsection{XRD results}

Figure 3 displays the XRD curves obtained on AIN templates supplied by MTI corp. implanted with $\mathrm{He}$ ions to different fluences at $\mathrm{RT}$ (up) and $550^{\circ} \mathrm{C}$ (down). The intense diffraction peak at $\mathrm{q} / \mathrm{H}=$ 0 , i. e., zero strain, highlighted by a dashed line, corresponds to the diffraction of the undamaged AlN layer located between the He implanted layer and the sapphire substrate. On the left of this main Bragg peak, a large tail of scattered intensity results from a gradient of dilatation of the lattice. For most conditions and all conditions at RT, an intense satellite peak is observed immediately on the left of the main Bragg peak. This satellite peak usually results from the diffraction of the near surface region that is only slightly damaged by implantation. The position of this peak thus gives the near surface strain value that will be called minimum strain, $\varepsilon_{\min }$, in the following. The intensity that is scattered far for the main Bragg peak on the extreme left results from a deep layer of material that is highly perturbed by He implantation. The corresponding strain will be called maximum strain, $\varepsilon_{\max }$. Between these two extremes, oscillations are observed that result from interferences between two layers of material that are equally strained on either side of the most strained region. The presence of interference fringes for both temperatures of implantation and up to the highest fluence indicates that the crystal coherency is maintained, which means that there is no continuous amorphous layer [48], as expected [39] and in accordance with TEM results. The relatively low scattered intensity that is observed for the highest measured strains, though, indicates a certain level of disorder, or point defect clustering, via a low Debye-Waller factor [42]. In particular, the highest strain, which is measured for the $550^{\circ} \mathrm{C}-1 \times 10^{17}$ $\mathrm{cm}^{-2}$ condition, is associated with the lowest intensity and thus, highest level of disorder. This is in complete agreement with the observation by TEM of a high density of extended defects as well as bubbles, and a higher damage level as compared to the RT $-1 \times 10^{17} \mathrm{~cm}^{-2}$ condition (see Fig.1 and 2). In addition, roughly, similar strains measured at $\mathrm{RT}$ and $550^{\circ} \mathrm{C}$ are associated with similar scattered intensity, which is likely the result of a similar level of disorder for similar elastic strain independently of the temperature of implantation.

The measured minimum and maximum strain values for these implantation conditions are reported in the figure 4 as a function of fluence. The strain values obtained on the AlN template supplied by MSE, for which the XRD curves are not displayed here, are also reported. At low fluence at $550^{\circ} \mathrm{C}$, the near surface or minimum strain is too low to be measured, i. e., the satellite peak and main Bragg 
peak are not dissociable on the XRD curves. The measured strains are fairly equal in MTI and MSE templates that were implanted in the same implantation runs, except for some slight differences observed for the highest measured strain values included in the dotted rectangle in the figure 4 . These differences do not exceed $10 \%$. In accordance with the increase of deposited nuclear energy, both the minimum and maximum strain values measured at RT and $550^{\circ} \mathrm{C}$ are observed to increase with the fluence in the considered range (Fig.4). The increase of the maximum strain is however not linear with the fluence. At $550^{\circ} \mathrm{C}$, a strong increase of strain is noticed between 3 and $7 \times 10^{16} \mathrm{~cm}^{-2}$. At RT, a similar strong increase of maximum strain is observed at higher fluence, between $7 \times 10^{16} \mathrm{~cm}^{-2}$ and $1 \times 10^{17} \mathrm{~cm}^{-2}$. From the figure 4 , it is also clearly seen that the near surface strain, $\varepsilon_{\min }$, is significantly lower at $550^{\circ} \mathrm{C}$ than at RT for all studied fluences. The maximum strain, $\varepsilon_{\max }$, is also observed to be lower at $550^{\circ} \mathrm{C}$ than at RT for fluences lower than $5 \times 10^{16} \mathrm{~cm}^{-2}$, but significantly higher otherwise.

The strain profiles obtained from the simulation of the XRD curves are reported in the figure 5 for MTI specimens. Similar strain profiles are obtained for MSE specimens. Since the simulation is mostly sensitive to the width of the strain profile that is closely related to the width of interference fringes on XRD curves, simulations could not be conclusive at low fluence for which no interference fringes are observed (see Fig. 3). Hence, strain profiles are only displayed for fluences between $5 \times 10^{16}$ $\mathrm{cm}^{-2}$ and $1 \times 10^{17} \mathrm{~cm}^{-2}$. Generally speaking, interference fringes have to be clearly resolved to get an accurate width and shape of the strain profile. For example, the last fringe on the XRD curve of the MTI specimen implanted at $550^{\circ} \mathrm{C}$ to the fluence of $5 \times 10^{16} \mathrm{~cm}^{-2}$ (see Fig.3) corresponds to strain values varying from 0.7 to $\varepsilon_{\max }=1.1 \%$. In this case, the sensitivity of the simulation to the shape of the strain profile is thus relatively weak since the width of the strain profile cannot be unambiguously determined for strain values lower than $0.7 \%$. For higher fluences and independently of the temperature of implantation, the width of the strain profile is accurately determined for strain values higher than a value between 1 and $1.5 \%$ roughly. In the near surface region, where the strain is relatively low, the shape of the strain profile cannot be accurately determined and may slightly vary from the one that is reported. In addition, as explained in the experimental section, it is difficult to obtain accurate information on the depth of the strain profile from such simulations. Two possible strain profiles are for example shown for the RT- $5 \times 10^{16} \mathrm{~cm}^{-2}$ condition : one is centered on the He concentration profile calculated by SRIM, the other on the vacancy concentration profile. They both result in the same calculated XRD curve. At $7 \times 10^{16} \mathrm{~cm}^{-2}$ at RT, the relatively high scattered intensity on the last fringe on the XRD curve suggests that the peak of strain is relatively close to the surface : in this case, the reported strain profile is accordingly centered on the vacancy concentration profile. At the highest fluence, an obvious proportion of the strain profile with the He concentration profile is noticed, which set the choice of the depth of the strain profile on that of the calculated profile of He concentration. The same clear proportion of the strain profile with the calculated He concentration profile was obtained at high fluences at $550^{\circ} \mathrm{C}$, i. e., $7 \times 10^{16}$ and $1 \times 10^{17} \mathrm{~cm}^{-2}$. The conditions for which this proportion is evidently observed are represented by a dotted rectangle in the figure 4 . The strain profile obtained at $550^{\circ} \mathrm{C}$ $5 \times 10^{16} \mathrm{~cm}^{-2}$ also seems to fit the He concentration profile for strain values $>0.8 \%$. Outside of these conditions, at lower fluence, when fringes are visible on XRD curves and the simulation is possible, the strain profile neither fits the He concentration profile nor the vacancy concentration profile calculated by SRIM. 


\section{Discussion}

\subsection{Comparison between MTI and MSE wafers}

A previous study performed on AlN layers grown on both sapphire and $\mathrm{SiC}$ substrates has shown a significant difference in the state of advancement of damage build-up induced by $\mathrm{He}$ implantation in the two materials [39]. A different density of native dislocations was suggested as the reason for this result. In the present study, two types of AlN layers grown on sapphire substrates supplied by different manufacturers were used. Although their rocking curves are considerably different (see section 2), implying a strong difference in the density of native dislocations as evidenced by TEM observations (compare for example Fig.1.(c) and Fig.2(b)), both materials show similar strain and damage build-up when implanted in the same implantation runs. In particular, the measured minimum and maximum strain values, $\varepsilon_{\min }$ and $\varepsilon_{\max }$, reported in Fig.4, are strikingly similar except for some implantation conditions, mostly at the highest fluences, where slight disparities are noticed. This means that the difference observed in the density of native dislocations has no or minimal role in the damage and strain induced by He implantation in the present conditions. When they occur, the disparities between the strain values measured in MTI and MSE specimens do not exceed $10 \%$ and mainly concern the maximum strain at high fluence. They are observed after a strong increase of maximum strain arising at different fluences for implantations at RT and at $550^{\circ} \mathrm{C}$, as evidenced in Fig.4, and at conditions for which the strain profile is clearly proportional to the He concentration profile calculated by SRIM, unlike other conditions. These slight discrepancies thus occur after a change of mechanism, visibly associated with $\mathrm{He}$, and are likely to be indicative of an increase of sensitivity of the elastic response of the material to the damage induced by He implantation at high He concentration. Most probably, the closer the material is to saturation of elastic strain, estimated to be around 4\% in Eu-implanted AlN [15] as well as in He-implanted AlN for other conditions (not published), the more sensitive it is to strain build-up and it may thus result in fluctuations in the maximum strain values measured at high fluence.

\subsection{Dynamic annealing and point defect recombination}

At relatively low fluence at RT, the strain profiles neither fit the $\mathrm{He}$ nor the vacancy concentration profiles calculated by SRIM. The strain profiles are much larger than the $\mathrm{He}$ concentration profile and the ratio $\varepsilon_{\max } / \varepsilon_{\min }$ is close to 2 for fluences up to $7 \times 10^{16} \mathrm{~cm}^{-2}$, i. e., before the strong increase of maximum strain visible in Fig.4. This is much lower than the SRIM calculated ratio of concentration of vacancies at the peak damage and at the surface which is higher than 3 , and which is the result of ballistic processes only, the interaction between created defects during dynamic annealing being completely neglected in the calculation. This therefore indicates strong dynamic annealing processes, either point defect recombination or creation of extended defects such as dislocations that would be efficient in relaxing elastic strain [49-50]. At low fluence, it is likely that no extended defects are formed, as it was found at $550^{\circ} \mathrm{C}$ (see $\S 3.1$.). The results thus suggest a significant point defect recombination already at RT in the deep perturbed region where the density of created point defects is maximal. This is in agreement with previous $\mathrm{RBS} / \mathrm{C}$ studies showing a significant dynamic annealing in ion implanted nitrides at temperatures as low as $\mathrm{LN}_{2}$ [51-52]. It was also previously suggested that both the anion and cation interstitials are mobile at $\mathrm{LN}_{2}$ in $\mathrm{AlN}$ irradiated with 
$2 \mathrm{MeV}$ Si ions, based on the observation of a well-developed network dislocation structure assumed to be formed by the growth and unfaulting of interstitial dislocation loops produced at lower doses [53].

At $550^{\circ} \mathrm{C}$, the minimum or near surface strain, $\varepsilon_{\min }$, is too low to be measurable on XRD curves for fluences lower than $5 \times 10^{16} \mathrm{~cm}^{-2}$. An efficient dynamic annealing resulting in minimal strain is very likely to occur in the concerned region where no He is implanted, and at fluences for which no extended defect, nor any contrasted region, is observed by TEM in the whole implanted layer (see §3.1.). As evidenced in Fig.4, the minimum strain is significantly lower at $550^{\circ} \mathrm{C}$ than at RT for the whole fluence range. This indicates an enhancement of dynamic annealing with efficient point defect recombination in the near surface region as the temperature of implantation is increased from RT to $550^{\circ} \mathrm{C}$. Vacancytype defects are very likely to be immobile at these temperatures. Previous studies on neutron irradiated AlN indeed suggest that vacancy migration occurs around $1000^{\circ} \mathrm{C}[30]$, which agrees well with recent calculations giving a migration energy of the nitrogen vacancy of 3,37 eV [5], corresponding to the $\mathrm{V}_{\mathrm{N}}$ annealing temperature of about $1000^{\circ} \mathrm{C}$ by using the Harmonic Transition State Theory [54]. Our results thus suggest an increased mobility of interstitial-type defects at $550^{\circ} \mathrm{C}$ compared to RT.

\subsection{Enhancement of strain by He mechanisms}

In the deep He-implanted region, the strain build-up has a peculiar behaviour. At fluences lower than $5 \times 10^{16} \mathrm{~cm}^{-2}$, the maximum strain, $\varepsilon_{\max }$, is lower at $550^{\circ} \mathrm{C}$ than at RT. As for the near surface strain $\varepsilon_{\min }$, it shows an enhancement of dynamic annealing related to point defect recombination with the increase of implantation temperature in the region where $\mathrm{He}$ is implanted. At fluences higher than $5 \times 10^{16} \mathrm{~cm}^{-2}$, the opposite effect is observed : the maximum strain is higher at $550^{\circ} \mathrm{C}$ than at RT. Another mechanism thus dominates the strain build-up. This is rather obvious when looking at the $550^{\circ} \mathrm{C}$ strain profiles in Fig. 5 where a change of shape is apparent in the region of maximum He concentration between 5 and $7 \times 10^{16} \mathrm{~cm}^{-2}$. This change of shape is visibly associated with an enhancement of strain and a resulting higher ratio $\varepsilon_{\max } / \varepsilon_{\min }$, in accordance with the strong increase of maximum strain visible in Fig.4. The same features are observed at RT for fluences higher than $7 \times 10^{16} \mathrm{~cm}^{-2}$. For these implantation conditions, the strain profiles are proportional to the He concentration profiles calculated by SRIM in the region of high He concentration. It shows, first, that He atoms implanted in the region of high $\mathrm{He}$ concentration do not significantly migrate at $550^{\circ} \mathrm{C}$, and second, that the strain build-up is dominated by mechanisms related to the presence of $\mathrm{He}$.

The figure 4 can thus roughly be divided into two parts, with an upper part (hatched zone) where mechanisms related to the presence of He dominate the strain build-up, and a lower part where the recombination of point defects prevails. It should be mentioned that the limit of the hatched area on the Fig. 4 is only a rough indication : it cannot be precisely determined by the current observations and could be placed slightly lower to include the strong increase of maximum strain, with a possible slight difference at $\mathrm{RT}$ and $550^{\circ} \mathrm{C}$. The point defect recombination and resulting efficient dynamic annealing is obvious with the relatively slow increase of strain with increasing fluence in the lower part in the Fig.4, i.e., at all fluences for the minimum or near surface strain, and at low fluences for the maximum strain. Both point defect recombination in the region free of $\mathrm{He}$ and He-related mechanisms are enhanced by an increase of implantation temperature, with opposite resulting effects on the strain. These He-related mechanisms precede the formation of visible bubbles as observed at $550^{\circ} \mathrm{C}$ at $1 \times 10^{17} \mathrm{~cm}^{-2}$. They are observed to induce a strong increase of maximum elastic strain for intermediate fluences, and 
are consequently understood as enhancing the concentration of free interstitials and possibly clusters of interstitials. This could result from an enhanced stabilization of vacancies by He atoms hindering point defect recombination, or by the additional emission of self-interstitials by mutation of preformed $\mathrm{He}-\mathrm{V}$ complexes, i. e., the trap mutation process, leading to the growth of $\mathrm{He}-\mathrm{V}$ complexes by creation of an additional vacancy. Once formed, the He- $\mathrm{V}$ complexes could effectively reduce the efficiency of point defect recombination by stabilizing vacancies created by cascades impinging in the vicinity of the complexes, and result in an enhanced free interstitial concentration and elastic strain. Both this mechanism and the trap mutation process would lead to the growth of $\mathrm{He}-\mathrm{V}$ complexes and to the formation of visible bubbles as seen at $550^{\circ} \mathrm{C}$. It seems, however, that the enhanced stabilization of vacancies by preformed $\mathrm{He}-\mathrm{V}$ complexes should not be significantly promoted by an increase in implantation temperature at temperatures where vacancies are known to be immobile in AlN, in contrast, probably, to a trap mutation process. Although there is relatively few studies on the subject, the formation of Frenkel Pairs by self-trapping in W has indeed already been shown to be a thermally activated event [55].

The results of the simulation of XRD curves for conditions included in the dotted rectangle in the Fig. 4 can be summed up as follows. In a deep layer of material where the concentration of He atoms is relatively high, the strain is proportional to the concentration of $\mathrm{He}$ with a proportionality constant that depends on the implantation temperature. For a given fluence $\phi$, and beyond a He concentration threshold, the strain at a depth $d$ can be written as :

$$
\begin{aligned}
& \varepsilon_{550, \phi, d}=\mathrm{K}_{550, \phi}[\mathrm{He}]_{d} \\
& \varepsilon_{\mathrm{RT}, \phi, d}=\mathrm{K}_{\mathrm{RT}, \phi}[\mathrm{He}]_{d} \\
& \text { with } \mathrm{K}_{550, \phi}>\mathrm{K}_{\mathrm{RT}, \phi}
\end{aligned}
$$

It means that for a given condition, beyond thresholds in fluence and $\mathrm{He}$ concentration, one $\mathrm{He}$ atom induces the same volume expansion independently on its location in this deep layer of material, $\mathrm{i}$. e., independently on the local He concentration. When comparing similar fluences, this volume expansion is higher at $550^{\circ} \mathrm{C}$. In the considered parameters range, the enhancement of free interstitial formation responsible for the strain enhancement, whether it results from an enhancement of vacancy stabilization or from trap mutation, is thus thermally activated but unexpectedly does not seem to significantly depend on the local He concentration beyond a threshold.

\subsection{Enhancement of damage}

After the strong increase of maximum strain, at conditions included in the dotted rectangle in the Fig.4. for which the strain profiles are clearly proportional to the He concentration profile, extended defects are visible by TEM. The present results show the strict coincidence of the dense layers of extended defects, both clusters observed with $\mathbf{g}=0002$, and BSFs observed with $\mathbf{g}=1 \overline{1} 00$ at the highest fluence at $550^{\circ} \mathrm{C}$, with that of visible bubbles. In addition to enhance the elastic strain, the presence of $\mathrm{He}$, and resulting bubbles at a later stage, is thus responsible for a strong enhancement of the formation of extended defects, as evidenced in a previous publication that has in particular shown the presence of bubbles on BSFs, or in their immediate vicinity [39]. The enhancement of formation of free interstitials that results from the He-related mechanisms is an obvious reason for this enhancement of extended defect formation. The observation of larger layers of defects at $550^{\circ} \mathrm{C}$ compared to RT at the same fluence of $1 \times 10^{17} \mathrm{~cm}^{-2}$ is in agreement with a higher maximum strain as well as higher observed damage 
at this temperature (see $\S 3.1$ ). The presence of bubbles is indeed only detected at $550^{\circ} \mathrm{C}$. In the absence of mobile vacancies $[5,30]$, this should result from the thermally activated detrapping of He atoms from small He-V complexes that migrate to larger and more stable complexes leading to faster nucleation and growth of visible bubbles at elevated temperature [56]. A thermally enhanced mechanism of trap mutation or loop punching could also contribute to this observation. The superimposition of the bubble layer on the $\mathrm{He}$ concentration profile calculated by SRIM gives a critical He concentration for the nucleation of visible bubbles at $550^{\circ} \mathrm{C}$ between 4 and $6 \times 10^{21} \mathrm{He} . \mathrm{cm}^{-3}$, i. e., between 4 and 6 at.\% roughly. It should be recalled that the simulation of XRD curves with the matching of the strain profile with SRIM He concentration profile indicates that He atoms should not significantly migrate in these conditions in the region of high He concentration. In another hand, TEM observations show that the bubble layer is not centered on the calculated He profile but rather between the calculated peaks of vacancy and He concentrations, explaining the relatively large range for the above-given critical $\mathrm{He}$ concentration for bubble nucleation. This location of the bubble layer is in agreement with earlier results on He-implanted AlN [39] and is consequently not related to uncertainty on the measurement on TEM micrographs. The swelling induced by both defects and bubbles should also be negligible in the present conditions. The depth of the He concentration profile calculated by SRIM might thus not be accurate, whilst its shape appears to be correct. Discrepancies were already reported in the range of light ions calculated by SRIM and deduced by TEM from the location of cavities in ceramics [9, 57], which were ascribed to incorrect electronic stopping power at intermediate implantation energy. But in contrast to the present results, the observed effect was a greater measured ion range. Alternatively, visible bubbles may only form in the region of relatively high vacancy concentration, whilst smaller undetectable He$\mathrm{V}$ complexes could form at the rear of the implanted region where the ratio $\mathrm{He} / \mathrm{vacancies}$ is high. Like the bubble layer, the main layers of extended defects are centered between the calculated peaks of vacancy and He concentrations, which is where the concentration of interstitials should be the highest.

\subsection{Comparison with previous studies on elastic strain build-up}

The figure 6 reports the evolution of minimum and maximum strain values obtained at RT as a function of dose in displacements per atom in comparison with values obtained in a previous study in RT Eu-implanted AIN [15]. Both He and Eu implantations were performed with similar fluxes, and the SRIM calculations for dpa estimation were performed in both cases with the parameters reported in section 2. For the minimum strain $\varepsilon_{\min }$ of He-implanted AlN, the number of dpa was averaged over 150 $\mathrm{nm}$ in the near surface region. The simulation of XRD curves indeed shows that the measured minimum strain value does not correspond to the strain immediately near the surface but rather to the average strain on an extended region from the surface. Integration of the strain profiles reported in Fig. 5 gives a width of about $150 \mathrm{~nm}$ for this region to accurately match the measured minimum strain value, although it is difficult to give a very accurate width since the simulation is not very sensitive to the shape of the strain profile in the near surface region. The figure 6 first shows a striking linear increase, highlighted by a dotted line, of the maximum strain in the case of Eu-implanted AlN in the dpa range between 0.02 and $10 \mathrm{dpa}$, corresponding to fluences ranging from $1 \times 10^{13}$ to $4.8 \times 10^{15} \mathrm{Eu}_{\mathrm{cm}}{ }^{-2}$, after which a saturation of the maximum strain was observed at close to $4 \%$ [15]. The minimum strain values obtained in He-implanted AlN in the present study superimpose well on the same strain vs. dpa line. The maximum strain values of the present study are however above the line : a strong deviation is in 
particular observed at high fluence with the obvious superlinearity of the dependence of maximum strain on ion dose. It thus suggests that the strain build-up behaves similarly in Eu-implanted AIN and in the surface of He-implanted AlN, where He atoms are not implanted, in the considered parameter range. Although the density of collision cascades is very different in both cases, it seems that the strain results from ballistic processes as well as similar dynamic annealing processes that occur with the same efficiency. This is in contradiction with a literature study showing the strong dependence of implantation-produced stable lattice disorder on the density of collision cascades in $\mathrm{GaN}$ and attributed to an increase in the efficiency of clustering of mobile point defects into stable defect complexes with increasing density of ion-beam-generated point defects [58]. This may however not apply to the whole range of ion mass, and this study is moreover based on RBS/C results that may not be comparable to the present XRD results, XRD being sensitive at much lower damage, before the formation of visible extended defects. The figure 6 shows that in the region where He is implanted, the strain build-up, and therefore production of stable point defects, appear much more efficient, especially at $2 \mathrm{dpa}$ where $\mathrm{He}$ mechanisms were seen to prevail.

A similar variation of maximum strain on ion dose has already been reported in He-implanted $\mathrm{SiC}$ at elevated temperature [59-60]. Whilst the maximum strain is seen to quickly saturate with ion dose in the case of $\mathrm{Ar}$ and $\mathrm{Xe}$ implanted $\mathrm{SiC}$, a deviation from this behavior is observed in the case of He-implanted $\mathrm{SiC}$ with a strong and specific increase of strain from relatively low dpa $(<1 \mathrm{dpa})[60]$. This was ascribed to the concentration of $\mathrm{He}$ atoms, large He-V complexes or bubble precursors formation, and excluded in the case of heavy gas due to the low concentration of gas atoms. Similarly, a chemical enhancement of damage build-up was observed using RBS/C in light ion implanted GaN, particularly in $\mathrm{C}$ and O-implanted $\mathrm{GaN}$ [58], in which the large concentration of implanted atoms was presumed to be accountable for an enhanced stability of irradiation-induced defects or amorphous phase. In He-implanted $\mathrm{SiC}$, the He-related defects induced by RT implantation were seen to play a dominant role on the $\mathrm{SiC}$ lattice expansion when He concentration exceeds 0.5 at.\% [34, 61]. In the present study, it can be roughly estimated that He mechanisms prevail on the strain build-up and overcome the point defect recombination from a critical He concentration of about 5 at.\% for RT implantation. This critical He concentration decreases with increasing implantation temperature with a very rough estimate of about 3 at. $\%$ at $550^{\circ} \mathrm{C}$. Approximately, an order of magnitude more $\mathrm{He}$ concentration is thus necessary to produce in AlN similar effects on the strain as in SiC. This is obviously the result of the strong dynamic annealing effects with in particular efficient point defect recombination occurring at relatively low fluence, and in general, in conditions reported in the lower part of the Fig.4. The evolution of the strain build-up as a function of He implantation temperature also show some differences in the two materials, AlN and SiC. Whilst, at relatively high fluence, the maximum strain is seen to increase with increasing implantation temperature from RT to $550^{\circ} \mathrm{C}$ in $\mathrm{AlN}$, the maximum strain obtained in $\mathrm{SiC}$ is always higher at $\mathrm{RT}$ than at elevated temperature in the range $200-800^{\circ} \mathrm{C}$, and in this temperature range, the only increase of maximum strain with implantation temperature is observed between 500 and $800^{\circ} \mathrm{C}$. In $\mathrm{SiC}$, in which the defect interaction processes are rather weak at RT resulting in no visible extended defects, the accumulation of point defects and undetectable defect complexes induces very large elastic strains, higher than $10 \%$, responsible for the collapse of the crystalline matrix into an amorphous phase [34]. In contrast, the strong defect interaction processes occurring in AlN as a result of a high mobility of point defects lead to recombination of point 
defects and extended defect formation that are known to relax the elastic strain [49], therefore resulting in weaker expansion of the lattice, which is somewhat similar to what occurs in metals in which the dynamic annealing processes are highly efficient. In comparison with materials with less efficient dynamic annealing, visible He-related mechanisms, which are associated with the nucleation and growth of $\mathrm{He}-\mathrm{V}$ complexes, are thus delayed to higher He concentration with obvious detrimental effects when increasing implantation temperature, i. e., a strong enhancement of strain and damage, due to the very high concentration of atoms involved.

\section{Conclusions}

The elastic strain build-up and damage induced by $50 \mathrm{keV} \mathrm{He}$ implantation at RT and $550^{\circ} \mathrm{C}$ into (0001)AlN were studied using a combination of XRD and TEM experiments. Evidence for strong dynamic annealing with efficient point defect recombination is reported at RT. The point defect recombination is found to be enhanced when increasing the implantation temperature from $\mathrm{RT}$ to $550^{\circ} \mathrm{C}$ in the near surface region where no He atoms are implanted, and at relatively low fluence in the Heimplanted region. In particular, the significant reduction of elastic strain in the near surface region indicates an increased mobility of interstitial-type defects. At higher fluence in the He-implanted region, once a critical $\mathrm{He}$ concentration estimated roughly at 5 at.\% (3at.\%) at RT $\left(550^{\circ} \mathrm{C}\right)$ is reached, a significant change of behavior is observed on the elastic strain build-up showing that mechanisms related to the presence of $\mathrm{He}$ and to the formation and growth of stable $\mathrm{He}-\mathrm{V}$ complexes overcome the point defect recombination. In this region, a strong increase of elastic strain is observed with increasing fluence, and the strain is higher for higher implantation temperature. The strong increase of strain in the He-implanted region immediately precedes conditions for which the strain profiles clearly fit the $\mathrm{He}$ concentration profiles calculated by SRIM in the region of relatively high He concentration. It shows first that $\mathrm{He}$ atoms do not significantly migrate at $\mathrm{RT}$ and $550^{\circ} \mathrm{C}$, and second, that the presence of $\mathrm{He}$ enhances the formation of free interstitials and possibly clusters of interstitials, whether by an enhanced stabilization of vacancies, possibly by preformed He-V complexes, or by an additional formation of interstitials by trap mutation of the He-V complexes. From the simulation of the XRD curves, it is concluded that the mechanism responsible for the enhancement of free interstitial formation is thermally activated but unexpectedly does not depend significantly on the local He concentration beyond a threshold, in the considered parameters range. Similarly, the build-up of damage is enhanced by both the presence of $\mathrm{He}$ and the increase in implantation temperature. For the highest considered fluence, only clusters of interstitials are observed at RT, whilst planar arrangement of bubbles and BSFs are additionally formed at $550^{\circ} \mathrm{C}$. The critical $\mathrm{He}$ concentration for the formation of visible bubbles at $550^{\circ} \mathrm{C}$ is estimated to be close to 4-6 at.\%. This enhancement of strain and damage is specific to a chemical effect of $\mathrm{He}$ atoms that are implanted in high concentration, which also occurs in other ceramics such as $\mathrm{SiC}$. In contrast to $\mathrm{SiC}$ and materials with lower efficiency of dynamic annealing, though, it is delayed to much higher He concentration and the increase in implantation temperature has visible detrimental effects on the microstructure evolution. 


\section{Acknowledgements}

The authors warmly thank the SEMIRAMIS staff at JANNuS-Orsay/SCALP (IJCLab) for He implantation.

\section{References}

[1] D. Wickramaratne, J.-X. Shen, C. E. Dreyer, A. Alkauskas, C. G. Van de Walle, Electrical and optical properties of iron in GaN, AlN, and InN, Phys. Rev. B 99 (2019) 205202.

[2] W. Sun, C. K. Tan, J. J. Wierer, and N. Tansu, Ultra-Broadband Optical Gain in III-Nitride Digital Alloys, Sci. Rep. 8 (2018) 3109.

[3] G. Li, W. Wang, W. Yang, Y. Lin, H. Wang, Z. Lin, and S. Zhou, GaN-based Light-Emitting Diodes on Various Substrates: A Critical Review, Rep. Prog. Phys. 79 (2016) 056501.

[4] S. Chowdhury, U. K. Mishra, Lateral and vertical transistors using the Algan/GAN Heterostructure, IEEE T. Electron Dev., 60 (2013) 3060-3066.

[5] Y. Gao, D. Sun, X. Jiang, and J. Zhao, Point defects in group III nitrides: A comparative firstprinciples study, J. Appl. Phys. 125 (2019) 215705

[6] J. Wu, W. Walukiewicz, K. M. Yu, W. Shan, J. W. Ager III, E. E. Haller, H. Lu, W. J. Schaff, W. K. Metzger, S. Kurtz, Superior radiation resistance of $\operatorname{In}_{1-x} \mathrm{Ga}_{x} \mathrm{~N}$ alloys: Full-solar-spectrum photovoltaic material system, J. Appl. Phys. 94 (2003) 6477-6482.

[7] S. O. Kucheyev, J. S. Williams, J. Zou, C. Jagadish, M. Pophristic, S. Guo, I. T. Ferguson, and M. Manasreh, Ion-beam-produced damage and its stability in AlN films, J. Appl. Phys. 92 (2002) 35543558 .

[8] A. K. Suri, N. Krishnamurthy, I. S. Batra, Materials issues in fusion reactors, J. Phys. Conf. Ser. 208 (2010) 012001.

[9] S. J. Zinkle, Effect of $\mathrm{H}$ and He irradiation on cavity formation and blistering in ceramics, Nucl. Instrum. Methods B 286 (2012) 4-19.

[10] L. L. Snead, R. H. Jones, A. Kohyama, P. Fenici, Status of silicon carbide composites for fusion, J. Nucl. Mater. 233-237 (1996) 26-36.

[11] T. Yano, T. Iseki, Swelling and microstructure of AlN irradiated in a fast reactor, J. Nucl. Mater. 203 (1993) 249-254.

[12] T. Yano, K. Ichikawa, M. Akiyoshi, Y. Tachi, Neutron irradiation damage in aluminum oxide and nitride ceramics up to a fluence of $4.2 \times 10^{26} \mathrm{n} / \mathrm{m}^{2}$, J. Nucl. Mater. 283-287 (2000) 947-951.

[13] T. Pornphatdetaudom, T. Yano, K. Yoshida, Physical property changes of neutron-irradiated aluminum nitride and their recovery behavior by annealing using a step-heating dilatometer, Nucl. Mater. Energy 16 (2018) 24-28. 
[14] K. Lorenz, E. Alves, T. Monteiro, M. J. Soares, M. Peres, P. J. M. Smulders, Optical doping of AlN by rare earth implantation, Nucl. Instrum. Methods B 242 (2006) 307-310.

[15] S. Leclerc, B. Lacroix, A. Declémy, K. Lorenz, and P. Ruterana, Mechanisms of damage formation in Eu-implanted AlN, J. Appl. Phys. 112 (2012) 073525.

[16] C. Ronning, M. Dalmer, M. Uhrmacher, M. Restle, U. Vetter, L. Ziegeler, H. Hofsäss, T. Gehrke, K. Järrendahl, R. F. Davis, Isolde Collaboration, Ion implanted dopants in GaN and AlN: Lattice sites, annealing behavior, and defect recovery, J. Appl. Phys. 87 (2000) 2149-2157.

[17] W. Jiang, I.-T. Bae, W. J. Weber, Disordering and dopant behaviour in Au+-ion-irradiated AlN, J. Phys. Condens. Matter 19 (2007) 356207.

[18] K. Lorenz, E. Alves, F. Gloux, P. Ruterana, M. Peres, A. J. Neves, T. Monteiro, Optical doping and damage formation in AlN by Eu implantation, J. Appl. Phys. 107 (2010) 023525.

[19] S. M. C. Miranda, N. Franco, E. Alves, K. Lorenz, Cd ion implantation in AlN, Nucl. Instrum. Methods B 289 (2012) 43-46.

[20] E. Wendler, W. Wesch, Ar implantation of InSb and AlN at $15 \mathrm{~K}$, Nucl. Instrum. Methods B 242 (2006) 562-564.

[21] I. Kim, L. Jiao, F. Khatkhatay, M. S. Martin, J. Lee, L. Shao, X. Zhang, J. G. Swadener, Y. Q. Wang, J. Gan, J. I. Cole, H. Wang, Size-dependent radiation tolerance in ion irradiated TiN/AlN nanolayer films, J. Nucl. Mater. 441 (2013) 47-53.

[22] M. Obradović, D. Pjević, D. Peruško, A. Grce, M. Milosavljević, K. P. Homewood, Z. Siketić, Effects of helium ion irradiation on bubble formation in AlN/TiN multilayered system, Thin Solid Films 591 (2015) 164-168.

[23] N. Kobayashi, H. Kobayashi, I. Sakamoto, N. Hayashi, Helium irradiation effects on structural properties of AlN thin films, J. Nucl. Mater. 179-181 (1991) 469-472.

[24] M. Zdorovets, K. Dukenbayev, A. Kozlovskiy, I. Kenzhina, Defect formation in AlN after irradiation with $\mathrm{He}^{2+}$ ions, Ceram. Int. 45 (2019) 8130-8137.

[25] J. F. Barbot, F. Pailloux, M.-L. David, L. Pizzagalli, E. Oliviero, G. Lucas, Helium implanted gallium nitride evidence of gas-filled rod-shaped cavity formation along the c-axis, J. Appl. Phys. 104 (2008) 043526.

[26] S. Agarwal, P. Trocellier, D. Brimbal, S. Vaubaillon, An experimental study of helium diffusion and helium induced microstructural evolution in ion implanted polycrystalline titanium nitride, Acta Mater. 121 (2016) 1-14.

[27] Y. Han, J. Peng, B. Li, Z. Wang, K. Wei, T. Shen, J. Sun, L. Zhang, C. Yao, N. Gao, X. Gao, L. Pang, Y. Zhu, H. Chang, M. Cui, P. Luo, Y. Sheng, H. Zhang, L. Zhang, X. Fang, S. Zhao, J. Jin, Y. Huang, C. Liu, P. Tai, D. Wang, W. He, Lattice disorder produced in GaN by He-ion implantation, Nucl. Instrum. Methods B 406 (2017) 543-547.

[28] D. Alquier, C. Bongiorno, F. Roccaforte, V. Raineri, Interaction between dislocations and Heimplantation-induced voids in GaN epitaxial layers, Appl. Phys. Lett. 86 (2005) 211911.

[29] H. Suematsu, T. E. Mitchell, T. Iseki, T. Yano, Hardening in AlN induced by point defects, Proc. Mater. Res. Soc. 235 (1991) 445. 
[30] T. Yano, M. Tezuka, H. Miyasaki, T. Iseki, Macroscopic length, lattice parameter and microstructural changes in neutron-irradiated aluminum nitride due to annealing, J. Nucl. Mater. 191194 (1992) 635-639.

[31] B. Lacroix, S. Leclerc, A. Declémy, K. Lorenz, E. Alves, P. Ruterana, Mechanisms of damage formation in Eu-implanted GaN probed by X-ray diffraction, Europhys. Lett. 96 (2011) 46002.

[33] S. M. C. Miranda, P. Kessler, J. G. Correia, R. Vianden, K. Johnston, E. Alves, K. Lorenz, Ion implantation of Cd and Ag into AlN and GaN, Phys. Status Solidi C 9 (No. 3-4) (2012) 1060-1064.

[34] S. Leclerc, M. F. Beaufort, J. F. Barbot, and A. Declémy, Strain and amorphization under lightion implantation in SiC, Europhys. Lett. 98 (2012) 46001.

[35] S. Leclerc, M. F. Beaufort, A. Declémy, Strain-induced drift of interstitial atoms in SiC implanted with helium ions at elevated temperature, J. F. Barbot, J. Nucl. Mater. 397 (2010) 132-134.

[36] JANNuS (Joint Accelerators for Nano-science and Nuclear Simulation), http://jannus.in2p3.fr and http://www.csnsm.in2p3.fr/MET.

[37] C.-O. Bacri, C. Bachelet, C. Baumier, J. Bourçois, L. Delbecq, D. Ledu, N. Pawels, S. Picard, S. Renouf, C. Tanguy, SCALP, a platform dedicated to material modifications and characterization under ion beam, Nucl. Instrum. Methods B 406 (2017) 48-52.

[38] J. F. Ziegler, M. D. Ziegler, J. P. Biersack, SRIM - The stopping and range of ions in matter (2010), Nucl. Instrum. Methods B 268 (2010) 1818-1823.

[39] S. Jublot-Leclerc, F. Pallier, L. Delauche, A. Declémy, Temperature dependent He-enhanced damage and strain in He-implanted AlN, J. Nucl. Mater. 523 (2019) 369-377.

[40] J. Xi, B. Liu, Y. Zhang, and W. Weber, Ab initio molecular dynamics simulations of AlN responding to low energy particle radiation, J. Appl. Phys. 123 (2018) 045904.

[41] S. M. C. Miranda, N. Franco, E. Alves, K. Lorenz, Cd ion implantation in AlN, Nucl. Instrum. Methods B 289 (2012) 43-46.

[42] P. H. Dederichs, Effect of defect clustering on anomalous x-ray transmission, Phys. Rev. B 1 (1970) 1306-1317. In the present publication, the static Debye-Waller factor is defined as exp(- $\left.\mathrm{L}_{\mathrm{h}}\right)$ in Dederichs notation.

[43] R. Balboni, S. Milita, and M. Servidori, On the role of the static Debye-Waller factor in X-ray rocking curve analysis, Phys. Status Solidi A 148 (1995) 95-105.

[44] S. Stepanov, GID-sl. <http://sergey.gmca.aps.anl.gov/gid_sl.html>.

[45] F. Gloux, T. Wojtowicz, P. Ruterana, K. Lorenz, E. Alves, Transmission electron microscopy investigation of the structural damage formed in $\mathrm{GaN}$ by medium range energy rare earth ion implantation, J. Appl. Phys. 100 (2006) 073520.

[46] E. Oliviero, C. Tromas, F. Pailloux, A. Declémy, M. F. Beaufort, C. Blanchard, J. F. Barbot, Damage formation and recovery in temperature helium implanted 4H-SiC, Mat. Sci. Eng. B 102 (2003) 289-292. 
[47] C. H. Zhang, S. E. Donnelly, V. M. Vishnyakov, J. H. Evans, Dose dependence of formation of nanoscale cavities in helium-implanted 4H-SiC, J. Appl. Phys. 94 (2003) 6017-6022.

[48] S. Leclerc, A. Declémy, M.F. Beaufort, C. Tromas, and J. F. Barbot, Swelling of SiC under helium implantation, J. Appl. Phys. 98 (2005) 113506.

[49] B. Vincent, J.-F. Damlencourt, V. Delaye, R. Gassilloud, L. Clavelier, Stacking fault generation during relaxation of silicon germanium on insulator layers obtained by the Ge condensation technique, Appl. Phys. Lett. 90 (2007) 074101.

[50] Z. H. Wu, T. Tanikawa, T. Murase, Y.-Y. Fang, C. Q. Chen, Y. Honda, M. Yamaguchi, H. Amano, N. Sawaki, Partial strain relaxation by stacking fault generation in InGaN multiple quantum wells grown on (11̄01) semipolar GaN, Appl. Phys. Lett. 98 (2011) 051902.

[51] S. O. Kucheyev, J. S. Williams, S. J. Pearton, Ion implantation into GaN, Mat. Sci. Eng. R 33 (2001) 51-107, and references therein.

[52] J. S. Williams, S. O. Kucheyev, H. H. Tan, J. Wong-Leung and C. Jagadish, Ion irradiation-induced disordering of semiconductors: defect structures and applications, Philos. Mag. 85 (2005) 677-687.

[53] S. J. Zinkle, L. L. Snead, W. S. Eatherly, J. W. Jones, and D. K. Hensley, Effect of low temperature ion irradiation on the microstructure of nitride ceramics, Mater. Res. Soc. Symp. Proc. 540 (1999) 305.

[54] A. Kyrtsos, M. Matsubara, and E. Bellotti, Migration mechanisms and diffusion barriers of carbon and native point defects in GaN, Phys. Rev. B 93 (2016) 245201

[55] J. Boisse, A. De Backer, C. Domain, C. S. Becquart, Modeling of the self trapping of helium and the trap mutation in tungsten using DFT and empirical potentials based on DFT, J. Mater. Res. 29 (2014) 2374-2386.

[56] R. W. Harrison, S. Ebert, J. A. Hinks, S. E. Donnelly, Damage microstructure evolution of helium ion

irradiated SiC under fusion relevant temperatures, J. Eur. Ceram. Soc. 38 (2018) 3718-3726.

[57] S. J. Zinkle, Microstructure of ion irradiated ceramic insulators, Nucl. Instrum. Methods B 91 (1994) 234-246.

[58] S. O. Kucheyev, J. S. Williams, C. Jagadish, J. Zou, G. Li, A. I. Titov, Effect of ion species on the accumulation of ion-beam damage in GaN, Phys. Rev. B 64 (2001) 035202.

[59] J.-F. Barbot, M.-F. Beaufort, A. Declémy, Strain build-up in SiC implanted at different temperatures, Nucl. Instrum. Methods B 327 (2014) 59-62.

[60] C. Jiang, J. Nicolaï, A. Declémy, E. Gilabert, M.-F. Beaufort, J.-F. Barbot, Implantation damage in heavy gas implanted 4H-SiC, Nucl. Instrum. Methods B 374 (2016) 71-75.

[61] S. Leclerc, M. F. Beaufort, A. Declémy, and J. F. Barbot, Evolution of defects upon annealing in He-implanted 4H-SiC, Appl. Phys. Lett. 93 (2008) 122101. 

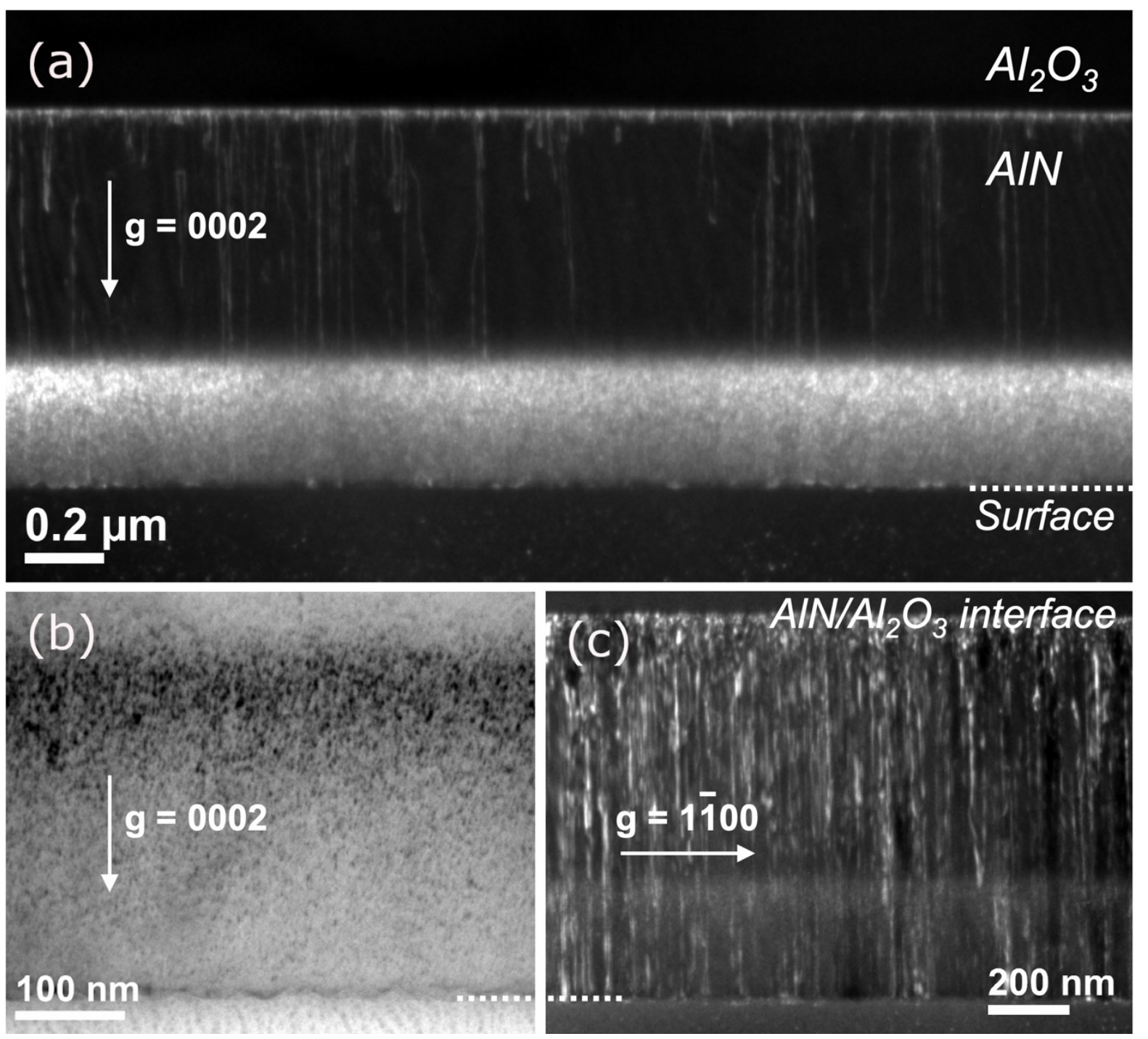

Fig. 1. Cross-sectional TEM micrographs of AlN monocrystalline layer from MTI corp. after $50 \mathrm{KeV}$ He implantation at RT to the fluence of $1 \times 10^{17} \mathrm{~cm}^{-2}$ : (a) weak-beam dark field using $\mathbf{g}=0002$, (b) bright field in two-beam condition using $\mathbf{g}=0002$, (c) weak-beam dark field using $\mathbf{g}=1 \overline{1} 00$. The position of the surface is indicated by a white dotted line. 

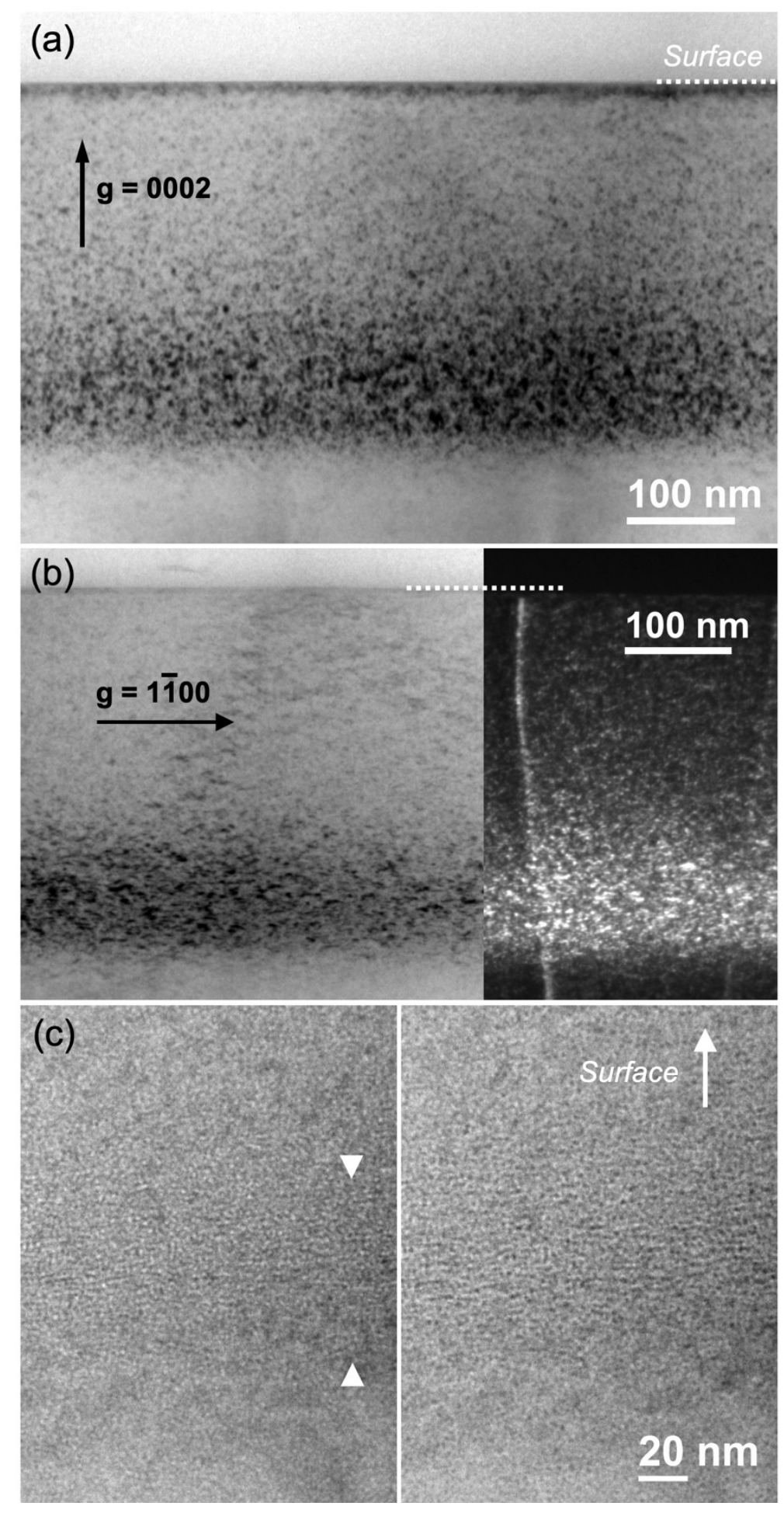

Fig. 2. Cross-sectional TEM micrographs of AlN monocrystalline layer from MSE supplies after 50 $\mathrm{keV}$ He implantation at $550^{\circ} \mathrm{C}$ to the fluence of $1 \times 10^{17} \mathrm{~cm}^{-2}$ : (a) bright field in two-beam condition using $\mathbf{g}=0002$, (b) bright field in two-beam condition (left) and weak-beam dark field (right) using $\mathbf{g}=1 \overline{1} 00$, (c) bubble layer observed in underfocus (left) and overfocus (right) conditions far from Bragg diffraction conditions. As expected for bubbles, they appear light in underfocus and dark in overfocus conditions. Usually, Fresnel fringes with a reverse contrast are observed surrounding the bubbles, which are not visible here due to the small size of the bubbles. The position of the bubble layer is roughly indicated by white arrows in (c). The position of the surface in (a) and (b) is indicated by a white dotted line. 


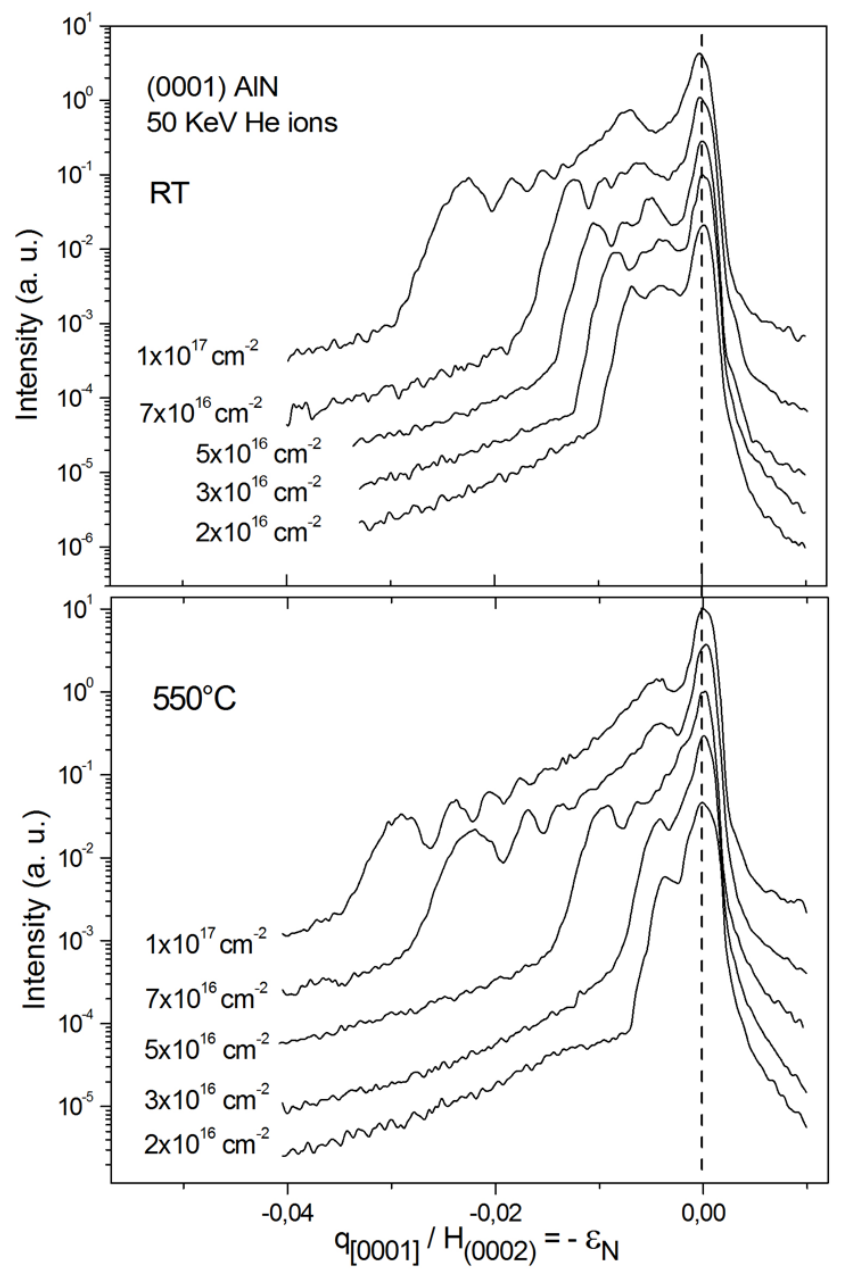

Fig. 3. X-ray scattered intensity distribution along the surface normal direction around the $(0002)$ reflection of AlN templates supplied by MTI corp. implanted with $50 \mathrm{keV}$ He ions at RT (up) and $550^{\circ} \mathrm{C}$ (down) to fluences ranging from $2 \times 10^{16}$ to $1 \times 10^{17} \mathrm{~cm}^{-2}$. The $\mathrm{x}$-axis is converted into $-\varepsilon_{\mathrm{N}}$, with $\varepsilon_{\mathrm{N}}$ the strain normal to the sample surface. 


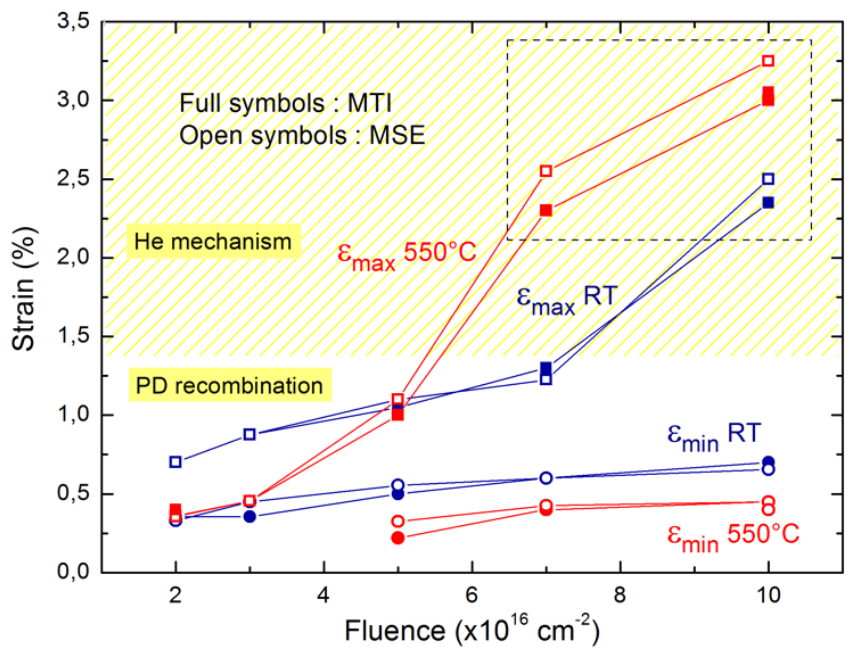

Fig. 4. Strain values estimated from XRD curves in AlN implanted with $50 \mathrm{keV}$ He ions at RT (blue) and $550^{\circ} \mathrm{C}$ (red). Both the minimum or near surface strain values, $\varepsilon_{\text {min }}$ (circles), and maximum strain values, $\varepsilon_{\max }$ (squares), are reported as a function of fluence. The results obtained on AlN templates supplied by MTI and MSE are reported with full and open symbols, respectively. The minimum and maximum fluence were reproduced twice at $550^{\circ} \mathrm{C}$ on MTI specimens. Some MSE or MTI spots are not visible because superimposed. A dotted rectangle indicates the conditions where the simulation of the XRD curves clearly results in a strain profile that closely matches the He concentration profile calculated by SRIM. The hatched area is where He-related mechanisms are found to prevail on the strain build-up (see section 4.3). PD stands for point defects. 


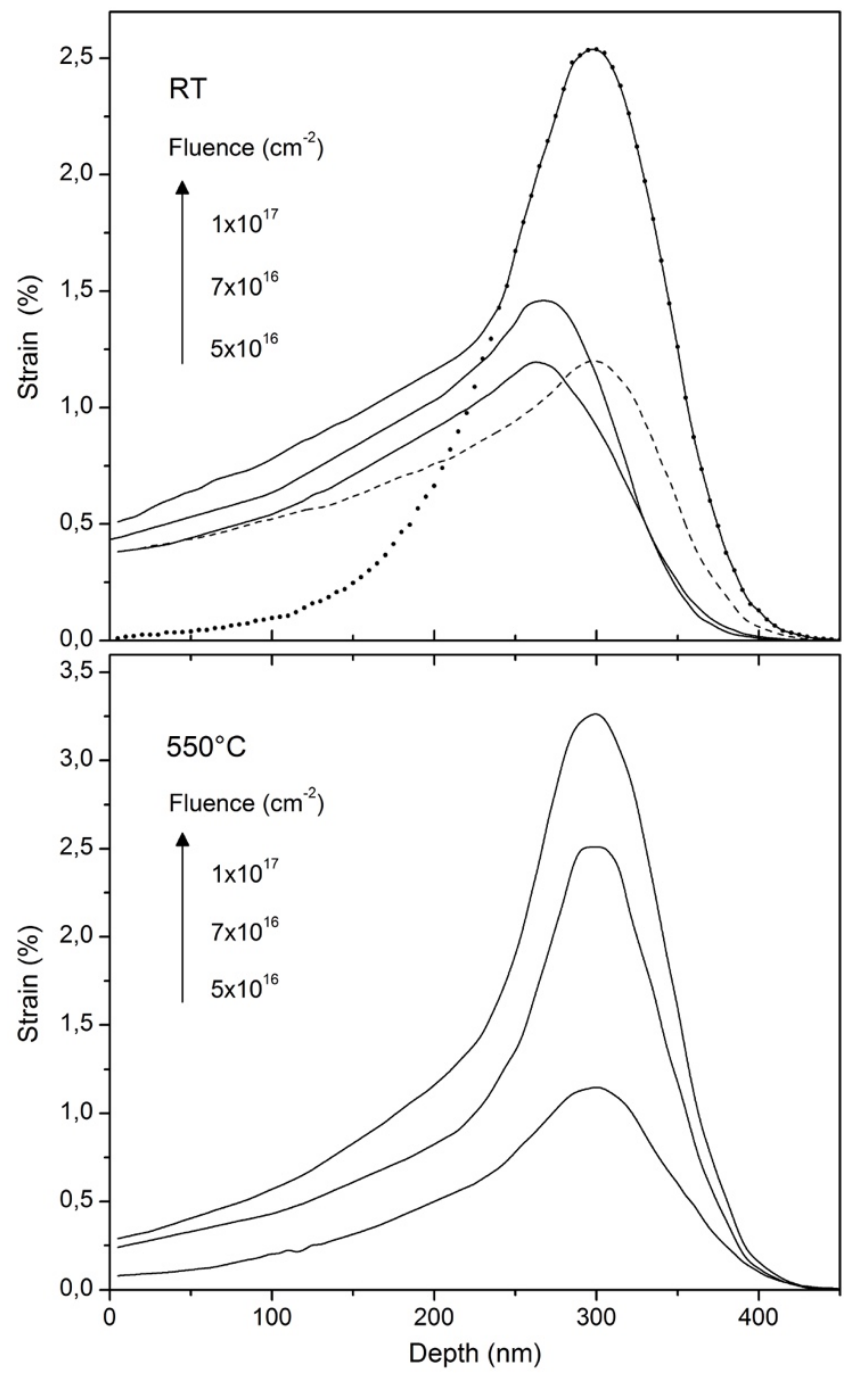

Fig. 5. Strain profiles obtained from the simulations of the XRD $\theta-2 \theta$ curves of MTI specimens implanted at RT (up) and $550^{\circ} \mathrm{C}$ (down) with $50 \mathrm{keV}$ He ions. The simulation is only weakly sensitive to the depth of the strain profile : two propositions of strain profiles peaking at different depths and resulting in the same calculated XRD curve are displayed in solid and dashed lines for the RT $-5 \times 10^{16}$ $\mathrm{cm}^{-2}$ condition. A He concentration profile calculated by SRIM is also reported in dotted line to show the close matching with the strain profile obtained for the RT-1 $\times 10^{17} \mathrm{~cm}^{-2}$ condition at strain values where the XRD simulation is very accurate in determining the width of the strain profile. 


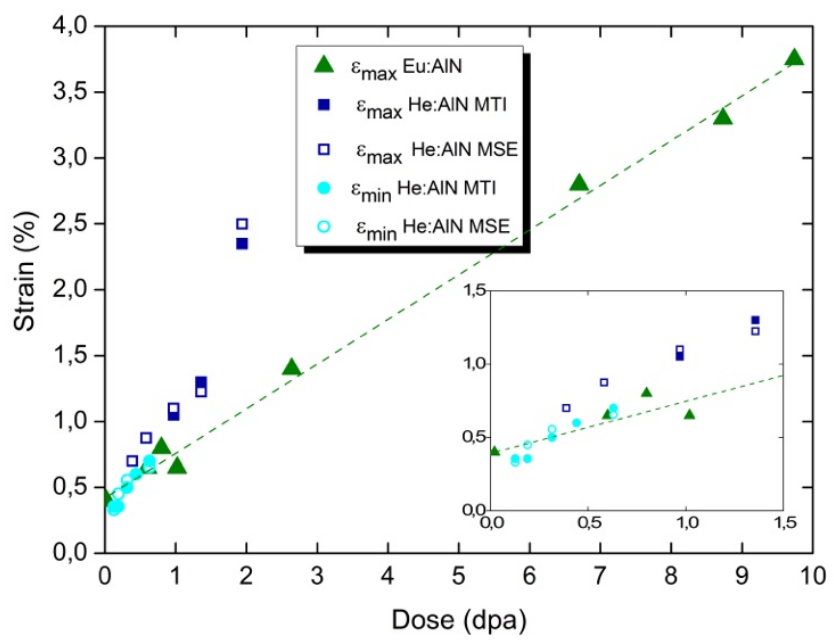

Fig. 6. Strain values as a function of dose in dpa in RT He-implanted and Eu-implanted AIN (data from a previous study [15]). SRIM calculations for dose estimations were all performed using the same parameters (see section 2). The number of dpa were averaged over $150 \mathrm{~nm}$ in the near surface region for the minimum strain $\varepsilon_{\min }$ (see text $\S 4.6$ for explanation). In the inset : magnification of the low dpa region. He and Eu implantations were performed with similar fluxes. 